Rev. Elet. em Gestão, Educação e Tecnologia Ambiental (e-ISSN: 2236-1170)

\title{
SENSAÇÃO TÉRMICA EM AMBIENTE URBANO A CÉU ABERTO NA CIDADE CUIABÁ-MT
}

\author{
Ivan Julio Apolonio Callejas \\ Professor do Departamento de Arquitetura e Urbanismo/ FAET/ UFMT, Doutor em Física Ambiental, Linha de \\ Pesquisa: Análise Microclimática em Sistemas Urbanos, E-mail: ivancallejas@ig.com.br
}

\section{Marta Cristina de Jesus Albuquerque Nogueira}

Professora do Departamento de Arquitetura e Urbanismo/ FAET/ UFMT, Professora do Programa de Pós-Graduação em Física Ambiental, Linha de Pesquisa: Análise Microclimática em Sistemas Urbanos, E-mail: mcjanp@gmail.com

$\underline{\text { http://dx.doi.org/10.5902/223611707701 }}$

\section{RESUMO:}

As condições meteorológicas do clima urbano influenciam a sensação térmica dos pedestres que circulam em ambientes a céu aberto. Desta forma, as variáveis meteorológicas desempenham importante papel para a qualidade vida das pessoas que fazem uso desses espaços, principalmente em cidades de Clima Tropical Continental. Nesse sentido, este trabalho objetivou mapear a sensação térmica de pedestres sob condição de céu aberto na cidade de Cuiabá-MT, levando em consideração apenas as condições meteorológicas desencadeadas pelo clima. Foram realizadas medições das variáveis meteorológicas e utilizou-se o Índice da Temperatura Fisiológica Equivalente (PET) para avaliação da sensação térmica. Durante o periodo diurno, o conforto térmico a céu aberto não foi alcançado em nenhum mês do ano na cidade de Cuiabá-MT. O mês de setembro se caracterizou como mês de maior frequência relativa de horas com desconforto térmico, com sensação variando de "ligeiramente quente" a "extremamente quente" na escala proposta por Matzarakis e Mayer, e "confortável" a "muito quente" na proposta por Monteiro e Alucci. Por outro lado, o mês de junho apresentou maior número de horas de conforto térmico, com sensação variando de "ligeramente frio" a "muito quente" na escala proposta por Matzarakis e Mayer, e "ligeirmante frio" a "quente" na escala proposta por Monteiro e Alucci. Os resultados evidenciam o quão disconfortáveis estão sujeitos os usuários dos espaços urbanos na cidade de Cuiabá-MT, o que demostra a importância do planejamento desses espaços, bem como a necessidade da promoção de sombreamento, seja ele artificial ou árbóreo, dos espaços com elevada frequência de utilização.

Palavras-chave: conforto térmico, temperatura fisiológica equivalente (PET), bioclimatologia

\section{THERMAL SENSATION IN URBAN ENVIRONMENT The OPEN SKY CITY CUIABÁ-MT}

\section{ABSTRACT:}

The weather conditions of the urban climate influence the thermal sensation of pedestrians moving in open environments. Thus, the meteorological variables play an important role for the quality life of the people who use these spaces, especially in cities Tropical Continental Climate. Thus, this study aimed to map the thermal sensation of walking under open condition in the city of Cuiabá, MT, taking into consideration only the weather triggered by climate. Were measured weather variables and used to index Physiological Equivalent Temperature (PET) for evaluating the thermal sensation. During the daytime period, thermal comfort in the open has not 
Rev. Elet. em Gestão, Educação e Tecnologia Ambiental (e-ISSN: 2236-1170)

been achieved in any month of the year in the city of Cuiabá-MT. The month of September was characterized as a month of higher relative frequency of hours with thermal discomfort with feelings ranging from "slightly warm" to "extremely hot" on the scale proposed by Matzarakis and Mayer, and "comfortable" to "very hot" in the proposal by Monteiro and Alucci. Moreover, the month of June had the greatest number of hours of thermal comfort, with sensation ranging from "slightly cold" to "hot" on the scale proposed by Matzarakis and Mayer, and "ligeirmante cold" to "hot" on the scale proposed by Monteiro and Alucci. The results show how users are subject disconfortáveis of urban spaces in the city of Cuiaba-MT, which demonstrates the importance of planning these spaces, as well as the need to promote shading, whether or artificial tree, spaces with high frequency of use.

Keywords: thermal comfort, physiological equivalent temperature (PET), bioclimatology.

\section{INTRODUÇÃO}

Vários estudos têm demonstrado que o clima urbano é caracterizado pela elevação da temperatura do ar, redução da umidade do ar e dos ventos, gerando nestes ambientes condições microclimáticas desagradáveis para as pessoas, principalmente nas cidades de climas tropicais (AYOADE, 2001; SANT'ANNA NETO, 2000; CALLEJAS, 2012).

A sensação térmica é um dos fatores mais importantes na decisão de permanência em um ambiente ao ar livre, pois fatores como temperatura e umidade do ar, velocidade do vento e a radiação solar interferem diretamente na sensação térmica dos pedestres, alterando a percepção, a preferência e a satisfação térmica das pessoas (Lin et al., 2010).

Outros aspectos do meio urbano como a geometria das edificações e o revestimento das superficies também exercem influência na sensação térmica das pessoas (LIN et al., 2010; CALLEJAS et al., 2012). A sensação térmica dos pedestres é uma variável dependente das condiçoes metereológicas, da morfologia urbana e da oportunidade adaptativa, sendo que esta última se refere ao grau com que uma pessoa pode se adaptar ao meio de forma física, fisiológica ou psicológica. Quando a oportunidade adaptativa é limitada, a satisfação térmica pode ser diferente da sensação térmica, fazendo com que lugares, a principio confortáveis termicamente, sejam considerados desconfortáveis, ocasionado estresse térmico. Isso acontece porque, conforme destaca Nikolopoulou (2001), fatores intrínsicos como naturalidade, experiências e expectativas, tempo de exposição e estímulo ambiental são importantes para a satisfação térmica do indivíduo.

A avaliação da sensação térmica pode ser feita a partir de vários índices, como o Voto Médio Previsto (VMP), proposto por Fanger (1972), Temperatura Efetiva (ET*) e Temperatura Efetiva Padrão (SET*), propostos por Gagge et al. (1986), a Temperatura Fisiológica Equivalente (PET), proposto por Hoppe (1999) e mais recentemente, o Indice Climático Térmico Universal (UTCI), proposto por Fiala et al. (2011). Os dois primeiros são utilizados para avaliar a sensação em ambientes internos, enquanto os últimos, ambientes internos e externos.

Para os ambientes a céu aberto, algumas pesquisas apontam que a temperatura radiante média e a velocidade do ar desempenham papel mais importante na sensação térmica do que a temperatura do ar, principalmente em condições de céu limpo (Xi et al., 2012). Desta forma, a avaliação destes parâmetros é fundamental na avaliação da sensação térmica de ambientes a céu aberto.

O PET foi introduzido por Höppe (1999) e baseia-se na equação de balanço térmico do corpo humano em condições de estabilidade. Seu valor é igual ao da temperatura do ar de um 
Rev. Elet. em Gestão, Educação e Tecnologia Ambiental (e-ISSN: 2236-1170)

ambiente interno de referência, no qual a temperatura interna corporal e a da pele são iguais àquelas sob as condições do ambiente considerado. Para esse ambiente de referência, os sequintes parêmetros foram estabelecidos: atividade moderada $(80 \mathrm{~W})$, resistência da roupa $(0,9$ clo), velocidade do $\operatorname{ar}(0,1 \mathrm{~m} / \mathrm{s})$, temperatura radiante média igual à temperatura do ar e pressão de vapor de $12 \mathrm{hPa}$, correspondente aproximadamente a $50 \%$ de umidade relativa à 20 으.

Segundo Matzarakis et al. (1999), em comparação com outros índices térmicos que também são obtidos a partir do balanço energético humano, tal como o Voto Médio Previsto (VMP), o PET tem a vantagem de ser traduzido na unidade de graus Celsius, amplamente conhecida, o que torna mais compreensível seus resultados, como por exemplo, para os planejadores urbanos, que geralmente não possuem familiariedade com a terminologia dos parâmetros biometeorológicos.

O índice PET pode ser estimado através do uso do software Rayman visto que este tem sido utilizado em áreas urbanas para gerar previsões precisas dos ambientes térmicos (Matzarakis et al., 1999). Dentre os fatores necessários para cálculo do PET, no modelo Rayman, cita-se a temperatura do ar (Tbs), umidade relativa (UR) ou pressão de vapor (e), velocidade do ar (v), vestimenta, atividade humana e temperatura média radiante (Trm), sendo este o fator mais importante, estimado por meio da temperatura de globo. Os limites do PET apresentados no trabalho de Matzarakis e Mayer (1996) para cidades européias (clima temperado) são expressos na Tabela 1.

No Brasil, o PET tem sido utilizado em várias pesquisas, principalmente com intuito de verificar a sua aplicabilidade como índice preditivo de sensação térmica de pessoas expostas a céu aberto (FAUSTINI e FONTES, 2010; LABAKI et al., 2012) e sob condições de sombreamento (ABREU e LABAKI, 2010; CALLEJAS et al., 2011). Algumas pesquisas se inserem no contexto de calibrá-lo como modelo preditivo de conforto e/ou estresse térmico, para a análise da adequação térmica de espaços abertos. Entre os trabalhos desenvolvidos, citam-se os de Monteiro e Alucci (2006), Monteiro e Alucci (2007) e Labaki et al. (2012) realizados no Estado de São Paulo e o de Hirashima el al. (2010) em Belo Horizonte, sendo que neste último, a amplitude térmica para o ano pesquisado não permitiu definir os intervalos referentes às situações climáticas de baixas temperaturas e o limite inferior de conforto térmico. Apresenta-se na Tabela 2 a calibração da percepção térmica realizada para a cidade de São Paulo (MONTEIRO e ALUCCI, 2007).

Tabela 01 - Percepção térmica e stress fisiológico para climas temperado e tropical

\begin{tabular}{c|c|c|c|c|c}
\hline PMV & $\begin{array}{c}\text { PET } \\
\left({ }^{\circ} \mathbf{C}\right)\end{array}$ & $\begin{array}{c}\text { Percepção Térmica } \\
\text { Matzarakis et al. (1999) }\end{array}$ & PMV & $\begin{array}{c}\text { PET } \\
\left({ }^{\circ} \mathbf{C}\right)\end{array}$ & $\begin{array}{c}\text { Percepção Térmica } \\
\text { Monteiro e Alucci (2007) }\end{array}$ \\
\hline$<-3,5$ & $<4$ & Muito Frio & & & Muito Frio \\
\hline$-3,5$ a $-2,5$ & 4 a 8 & Muito Frio a Frio & $<-3$ & $<4$ & -3 a -2 \\
\hline$-2,5$ a $-1,5$ & 8 a 13 & Frio a Ligeiramente frio 12 & Frio a ligeiramente frio \\
\hline$-1,5$ a $-0,5$ & 13 a 18 & Ligeiramente frio a Confortável & -2 a -1 & 12 a 18 & Ligeiramente frio a confortável \\
\hline$-0,5$ a 0,5 & 18 a 23 & Confortável & -1 a 1 & 18 a 26 & Confortável \\
\hline 0,5 a 1,5 & 23 a 29 & $\begin{array}{c}\text { Confortável a Ligeiramente } \\
\text { quente }\end{array}$ & 1 a 2 & 26 a 31 & $\begin{array}{c}\text { Confortável a Ligeiramente } \\
\text { quente }\end{array}$ \\
\hline 1,5 a 2,5 & 29 a 35 & Ligeiramente quente a Quente & 2 a 3 & 31 a 41 & Ligeiramente quente a Quente \\
\hline 2,5 a 3,5 & 35 a 41 & Quente a Muito Quente & $>3$ & $>41$ & Quente \\
\hline
\end{tabular}

Fonte: Matzarakis e Mayer (1996) - cidades européias; Monteiro e Alucci (2007) - cidade de São Paulo

A avaliação da sensação térmica em ambientes urbanos externos é complexa, tendo em vista a heterogeneidade dos ambientes ao ar livre e se faz necessária para fornecimento de 
parâmetros, com vistas ao planejamento urbano, no sentido de subsidiá-los no que se refere às questões de conforto térmico.

Nesse sentido, este trabalho objetivou avaliar a sensação térmica em espaços urbanos a céu aberto, a partir do índice preditivo Temperatura Fisiologica Equivalente (PET), com vistas a verificar a sua aplicabilidade na cidade de Cuiabá-MT. Questões como morfologia urbana e percepção térmica não são tratadas neste trabalho, sendo objeto de pesquisas futuras.

\section{MATERIAIS E MÉTODO}

\subsection{Local da pesquisa}

A pesquisa foi desenvolvida no ambiente urbano da cidade de Cuiabá, localizada na porção Centro-Sul do Estado Mato Grosso, no limite ocidental dos domínios do Cerrado e próximo à borda leste do Pantanal Mato-grossense. Atualmente, conta com cerca de 551.310 habitantes (IBGE, 2011) e possui cerca de $3.538,17 \mathrm{~km}^{2}$, sendo que $254,57 \mathrm{~km}^{2}$ correspondem à área de macrozona urbana e $3.283,60 \mathrm{~km}^{2}$ à área rural. Encontra-se localizada na província geomorfológica denominada Baixada Cuiabana. As altitudes variam de 146 a 259 metros (IPDU, 2009). A cobertura vegetal é constituída por remanescentes de cerrado, cerradão, matas ciliares no entorno dos rios, e por vegetação exótica (Figura 1).

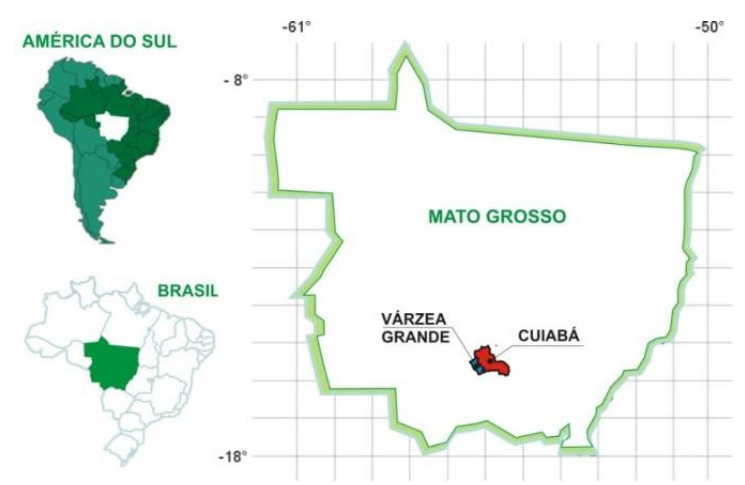

Figura 01 - Localização da região do estudo

O clima dominante é do tipo tropical continental semi-úmido (classificação $A w$ de Köppen), sendo a sua principal característica a presença constante de temperaturas elevadas, registrando média anual em torno de 250 a 26 드, com duas estações bem definidas: uma seca (outono-inverno) e uma chuvosa (primavera-verão) (MAITELLI, 1994). O índice pluviométrico anual varia de 1250 a 1500 mm (CAMPELO JUNIOR et al., 1991). Para Duarte (2000), o clima da região é definido por três períodos: uma estação seca e mais fresca no inverno; uma estação de transição seca e mais quente, um pouco antes das chuvas e, uma estação úmida e quente, durante as chuvas do verão.

A área urbana selecionada para estudo denominada de Sítio 1 se localiza na região leste da cidade, no bairro Areão $\left(15^{\circ} 35^{\prime} 47,83 \mathrm{~S}, 5^{\circ} 04^{\prime} 45,10 \mathrm{~W}, 196,83 \mathrm{~m}\right)$ distante do centro da cidade de aproximadamente $1,71 \mathrm{~km}$ (Figura 1 ). 0 ponto de coleta de dados para o estudo bioclimático está inserido no pátio central de uma escola da Rede Pública Estadual de Ensino. 


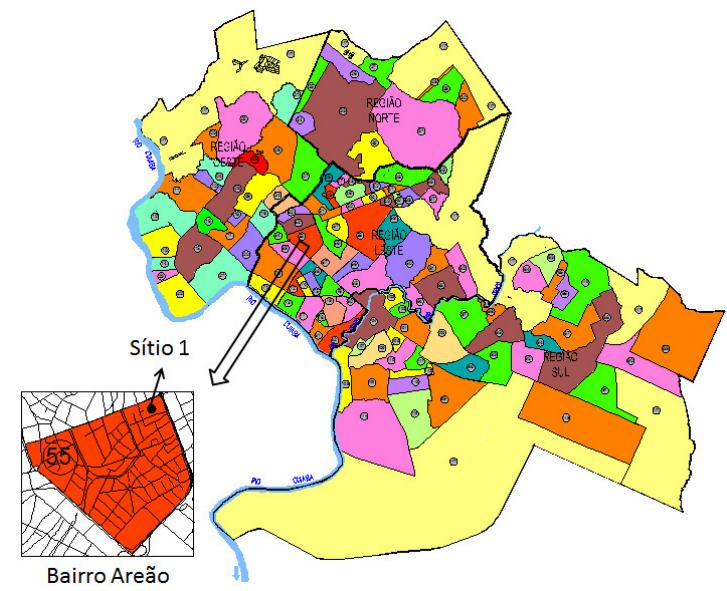

Figura 02 - Localização do ponto de coleta das variáveis bioclimáticas na cidade de Cuiabá-MT

\subsection{Materiais}

As variáveis para avaliação da sensação de conforto térmico foram obtidas por meio de medição no local definido para pesquisa. A temperatura e umidade do ar foram medidas por registrador automático, marca $\mathrm{HOBO}$, modelo U13, disposto no interior de abrigo meteorológico a $1,5 \mathrm{~m}$ de altura em relação ao nível do solo. No canal externo do registrador foi monitorada a temperatura de globo utilizando-se uma esfera de plástico de 2,5" de diâmetro (Souza et al., 2002), fixada em suporte na parte superior do abrigo a 1,7m de altura em relação ao nível do solo. A velocidade do ar foi medida a partir de estação meteorológica instalada junto ao abrigo meteorológico, em altura de 5 metros do nível do solo (Figura 3). Os dados da velocidade do ar foram posteriormente convertidos para o nível da altura dos sensores de temperatura e umidade do ar para avaliação da sensação térmica dos pedestres. A coleta de dados iniciou em 01 de setembro de 2010 e finalizou em 31 de agosto de 2011, abrangendo desta forma todas as estações climáticas da região.

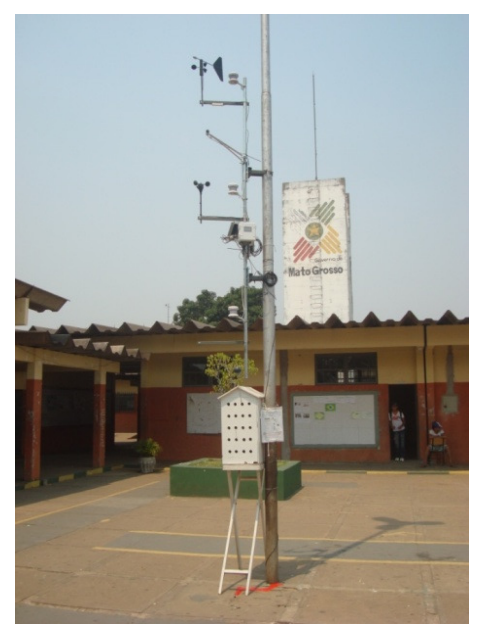

Figura 03 - Abrigo e estação meteorológica instalados no pátio central da escola estadual que serviu de base para a coleta de dados 
Rev. Elet. em Gestão, Educação e Tecnologia Ambiental (e-ISSN: 2236-1170)

\subsection{Método}

A sensação de conforto térmico foi avaliada pelo índice PET, utilizando-se o software RayMan 1.2, desenvolvido por Matzarakis et al. (2011), cujos dados de entrada foram as coordenadas geográficas e altitude do ponto de coleta, umidade relativa do ar (UR), temperatura do $\operatorname{ar}$ (Tbs), velocidade do vento (v) e temperatura radiante (Trm) calculada conforme metodologia proposta por Souza et al. (2002) e equação estabelecida pela ISO 7726 (1998). Para as características físicas das pessoas, adotaram-se as padronizadas pelo método preditivo PET, a saber: altura de $1,75 \mathrm{~m}$, peso de $75 \mathrm{~kg}$, vestimenta de $0,9 \mathrm{clo}$, sexo masculino e atividade com taxa metabólica de 80W.

Foram elaborados mapas de sensação térmica a partir da escala definida por Matzarakis e Mayer (1996) para países europeus e por Monteiro e Alucci (2007) para cidade de São Paulo.

\section{RESULTADOS E DISCUSSÕES}

O mapeamento apresentado na Figura 4 demonstra a modificação da sensação térmica ao longo dos dias e meses do ano para o período e região pesquisados, tanto para escala proposta por Matzarakis e Mayer (Figura 4a) quanto para a escala proposta por Monteiro e Alucci (Figura 4b). Uma análise geral do mapeamento permite inferir que as sensações térmicas preponderantes, segundo a escala proposta para cidades européias, variam desde "ligeiramente quente" a "extremamente quente", com poucas horas alcançando a faixa de conforto térmico. Para a escala proposta para a cidade de São Paulo, nota-se maior equilíbrio entre as horas de conforto (faixa neutra) e desconforto térmico ("ligeiramente quente" a "muito quente").

Pelos mapeamentos, foi possível verificar que as maiores intensidades de estresse térmico ocorreram no mês de setembro (transição entre inverno e primavera), enquanto que, as menores no mês de junho (inverno). 0 mês de setembro foi caracterizado por maior média diária de sensação térmica $\left(33,5^{\circ} \mathrm{C}\right)$, com variação gradativa de "ligeiramente quente" a "extremamente quente" para a escala de Matzarakis e Mayer, e de "confortável" a "muito quente" para a de Monteiro e Alucci, sendo que o valor máximo alcançado foi de $44,5^{\circ} \mathrm{C}$ às 14 horas. Este comportamento é justificado pela restrição hidrica imposta à região nesse período, pouca presença de nuvens no céu e ao fenômeno de queimadas. O mês de junho foi caracterizado como o de menor estresse térmico, com variação da sensação térmica de "ligeiramente frio" a "muito quente" para a escala de Matzarakis e Mayer, e de "ligeiramente frio" a "quente" na de Monteiro e Alucci, sendo o valor mínimo de $17,7^{\circ} \mathrm{C}$ às 6 horas da manhã, resultado da posição do sol no solstício de inverno e a ocorrência de "frente frias" na região nesse período. Os demais meses apresentaram comportamento intermediário aos descritos anteriormente.

A análise das frequências relativas anuais para a escala proposta por Matzarakis e Mayer (Tabela 2) indicou que são poucas as horas anuais que se encontram dentro da faixa de conforto (apenas 13\%). A maior frequência foi observada na escala de "ligeiramente quente" (43\%). Isso demonstra que pessoas adaptadas à região de clima temperado quando expostas a clima tropical, apresentarão "estresse ao calor" até que a aclimatação não aconteça. Por outro lado, quando se analisou a escala de Monteiro e Alucci, adaptada para as condições de clima tropical (Tabela 3), constatou-se maior frequência relativa de horas dentro da faixa de conforto (39\%), enquanto que a sensação de "quente" ficou com a segunda maior frequência relativa (34\%). A sensação de frio raramente foi observada na região, apenas em junho, com $1 \%$ das horas, tanto na escala de clima temperado quanto na tropical. A sensação de "muito quente" foi maior na escala proposta por Matzarakis e Mayer (22\%) do que na escala de Monteiro e Alucci (2\%), o que demostra que as pessoas que habitam locais de clima tropical estão mais adaptadas ao calor do que as de clima temperado. 


\section{REGETAUFSM}

CALLEJAS \& NOGUEIRA, v(9), no 9, p. 1946-1958, FEV, 2013.

Rev. Elet. em Gestão, Educação e Tecnologia Ambiental (e-ISSN: 2236-1170)

\begin{tabular}{|c|cccccccccccccccccccccccc|c|c|}
\hline Hora & $00: 00$ & $01: 00$ & $02: 00$ & $03: 00$ & $04: 00$ & $05: 00$ & $06: 00$ & $07: 00$ & $08: 00$ & $09: 00$ & $10: 00$ & $11: 00$ & $12: 00$ & $13: 00$ & $14: 00$ & $15: 00$ & $16: 00$ & $17: 00$ & $18: 00$ & $19: 00$ & $20: 00$ & $21: 00$ & $22: 00$ & $23: 00$ \\
\hline Set & 28.6 & 27.5 & 27.0 & 26.8 & 25.8 & 25.4 & 25.3 & 26.7 & 30.8 & 34.3 & 37.6 & 40.7 & 42.5 & 43.9 & 44.5 & 43.8 & 41.8 & 38.7 & 34.9 & 33.1 & 32.1 & 31.1 & 30.2 & 29.5 \\
Out & 25.6 & 25.3 & 24.6 & 24.4 & 23.9 & 23.7 & 23.6 & 25.8 & 29.3 & 31.5 & 34.7 & 36.4 & 38.1 & 39.1 & 39.8 & 38.5 & 36.3 & 35.1 & 31.5 & 29.9 & 28.7 & 27.9 & 27.3 & 26.5 \\
Nov & 25.0 & 24.4 & 24.0 & 23.7 & 23.5 & 23.3 & 23.7 & 27.0 & 30.3 & 32.1 & 32.8 & 33.2 & 35.3 & 36.9 & 37.2 & 36.7 & 35.3 & 33.3 & 29.8 & 27.9 & 26.9 & 26.4 & 25.8 & 25.4 \\
Dez & 26.6 & 26.4 & 26.3 & 26.0 & 25.8 & 25.5 & 25.5 & 28.1 & 32.0 & 35.0 & 36.6 & 38.3 & 41.1 & 39.9 & 39.6 & 37.4 & 35.7 & 33.8 & 30.5 & 28.6 & 28.0 & 27.6 & 27.3 & 26.9 \\
Jan & 25.6 & 25.3 & 25.1 & 24.9 & 24.7 & 24.4 & 24.5 & 26.1 & 29.6 & 32.9 & 34.6 & 35.7 & 38.4 & 38.0 & 38.1 & 36.4 & 34.7 & 33.1 & 30.2 & 28.0 & 27.3 & 26.8 & 26.4 & 26.1 \\
Fev & 24.6 & 24.2 & 23.9 & 23.8 & 23.5 & 23.3 & 23.4 & 24.1 & 27.1 & 30.7 & 32.5 & 33.0 & 35.8 & 36.1 & 36.6 & 35.3 & 33.6 & 32.4 & 29.8 & 27.4 & 26.5 & 26.0 & 25.4 & 25.2 \\
Mar & 24.2 & 24.1 & 23.8 & 23.7 & 23.6 & 23.6 & 23.5 & 24.1 & 26.8 & 29.7 & 32.2 & 35.4 & 36.6 & 35.6 & 35.6 & 35.4 & 32.6 & 30.1 & 27.2 & 25.9 & 25.2 & 25.0 & 24.7 & 24.6 \\
Abr & 25.6 & 25.3 & 25.0 & 24.6 & 24.3 & 24.2 & 23.9 & 24.3 & 29.4 & 33.8 & 36.6 & 39.1 & 39.7 & 40.8 & 40.1 & 38.8 & 36.6 & 34.1 & 29.5 & 28.0 & 27.0 & 26.4 & 26.2 & 25.9 \\
Mai & 21.9 & 21.4 & 20.9 & 20.5 & 19.9 & 19.5 & 19.0 & 19.0 & 22.8 & 28.0 & 30.9 & 33.7 & 35.5 & 36.5 & 36.8 & 36.8 & 35.2 & 31.3 & 27.5 & 26.1 & 24.9 & 23.9 & 23.2 & 22.6 \\
Jun & 21.5 & 21.1 & 20.3 & 19.8 & 19.3 & 18.6 & 17.9 & 17.7 & 20.7 & 27.5 & 31.2 & 33.7 & 35.8 & 37.3 & 37.7 & 37.6 & 36.0 & 31.5 & 27.8 & 26.1 & 24.6 & 23.4 & 22.5 & 22.0 \\
Jul & 21.7 & 21.1 & 20.5 & 20.1 & 19.0 & 18.4 & 18.4 & 18.1 & 20.9 & 27.4 & 30.9 & 33.5 & 36.0 & 37.0 & 38.0 & 38.0 & 36.9 & 33.5 & 28.5 & 26.7 & 25.4 & 24.3 & 23.2 & 22.1 \\
Ago & 23.6 & 22.8 & 21.8 & 20.9 & 20.3 & 19.5 & 19.1 & 19.1 & 24.0 & 30.2 & 33.7 & 36.2 & 38.2 & 39.1 & 40.0 & 39.6 & 39.0 & 35.9 & 30.3 & 28.5 & 27.3 & 25.9 & 25.1 & 24.3 \\
\hline
\end{tabular}

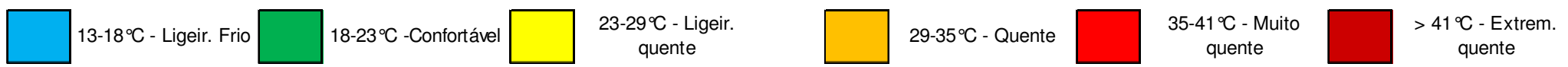

a) Escala de sensação térmica proposta por Matzarakis e Mayer (1996) para a Europa

\begin{tabular}{|c|ccccccccccccccccccccccccc|}
\hline Hora & $00: 00$ & $01: 00$ & $02: 00$ & $03: 00$ & $04: 00$ & $05: 00$ & $06: 00$ & $07: 00$ & $08: 00$ & $09: 00$ & $10: 00$ & $11: 00$ & $12: 00$ & $13: 00$ & $14: 00$ & $15: 00$ & $16: 00$ & $17: 00$ & $18: 00$ & $19: 00$ & $20: 00$ & $21: 00$ & $22: 00$ & $23: 00$ \\
\hline Set & 28.6 & 27.5 & 27.0 & 26.8 & 25.8 & 25.4 & 25.3 & 26.7 & 30.8 & 34.3 & 37.6 & 40.7 & 42.5 & 43.9 & 44.5 & 43.8 & 41.8 & 38.7 & 34.9 & 33.1 & 32.1 & 31.1 & 30.2 & 29.5 \\
Out & 25.6 & 25.3 & 24.6 & 24.4 & 23.9 & 23.7 & 23.6 & 25.8 & 29.3 & 31.5 & 34.7 & 36.4 & 38.1 & 39.1 & 39.8 & 38.5 & 36.3 & 35.1 & 31.5 & 29.9 & 28.7 & 27.9 & 27.3 & 26.5 \\
Nov & 25.0 & 24.4 & 24.0 & 23.7 & 23.5 & 23.3 & 23.7 & 27.0 & 30.3 & 32.1 & 32.8 & 33.2 & 35.3 & 36.9 & 37.2 & 36.7 & 35.3 & 33.3 & 29.8 & 27.9 & 26.9 & 26.4 & 25.8 & 25.4 \\
Dez & 26.6 & 26.4 & 26.3 & 26.0 & 25.8 & 25.5 & 25.5 & 28.1 & 32.0 & 35.0 & 36.6 & 38.3 & 41.1 & 39.9 & 39.6 & 37.4 & 35.7 & 33.8 & 30.5 & 28.6 & 28.0 & 27.6 & 27.3 & 26.9 \\
Jan & 25.6 & 25.3 & 25.1 & 24.9 & 24.7 & 24.4 & 24.5 & 26.1 & 29.6 & 32.9 & 34.6 & 35.7 & 38.4 & 38.0 & 38.1 & 36.4 & 34.7 & 33.1 & 30.2 & 28.0 & 27.3 & 26.8 & 26.4 & 26.1 \\
Fev & 24.6 & 24.2 & 23.9 & 23.8 & 23.5 & 23.3 & 23.4 & 24.1 & 27.1 & 30.7 & 32.5 & 33.0 & 35.8 & 36.1 & 36.6 & 35.3 & 33.6 & 32.4 & 29.8 & 27.4 & 26.5 & 26.0 & 25.4 & 25.2 \\
Mar & 24.2 & 24.1 & 23.8 & 23.7 & 23.6 & 23.6 & 23.5 & 24.1 & 26.8 & 29.7 & 32.2 & 35.4 & 36.6 & 35.6 & 35.6 & 35.4 & 32.6 & 30.1 & 27.2 & 25.9 & 25.2 & 25.0 & 24.7 & 24.6 \\
Abr & 25.6 & 25.3 & 25.0 & 24.6 & 24.3 & 24.2 & 23.9 & 24.3 & 29.4 & 33.8 & 36.6 & 39.1 & 39.7 & 40.8 & 40.1 & 38.8 & 36.6 & 34.1 & 29.5 & 28.0 & 27.0 & 26.4 & 26.2 & 25.9 \\
Mai & 21.9 & 21.4 & 20.9 & 20.5 & 19.9 & 19.5 & 19.0 & 19.0 & 22.8 & 28.0 & 30.9 & 33.7 & 35.5 & 36.5 & 36.8 & 36.8 & 35.2 & 31.3 & 27.5 & 26.1 & 24.9 & 23.9 & 23.2 & 22.6 \\
Jun & 21.5 & 21.1 & 20.3 & 19.8 & 19.3 & 18.6 & 17.9 & 17.7 & 20.7 & 27.5 & 31.2 & 33.7 & 35.8 & 37.3 & 37.7 & 37.6 & 36.0 & 31.5 & 27.8 & 26.1 & 24.6 & 23.4 & 22.5 & 22.0 \\
Jul & 21.7 & 21.1 & 20.5 & 20.1 & 19.0 & 18.4 & 18.4 & 18.1 & 20.9 & 27.4 & 30.9 & 33.5 & 36.0 & 37.0 & 38.0 & 38.0 & 36.9 & 33.5 & 28.5 & 26.7 & 25.4 & 24.3 & 23.2 & 22.1 \\
Ago & 23.6 & 22.8 & 21.8 & 20.9 & 20.3 & 19.5 & 19.1 & 19.1 & 24.0 & 30.2 & 33.7 & 36.2 & 38.2 & 39.1 & 40.0 & 39.6 & 39.0 & 35.9 & 30.3 & 28.5 & 27.3 & 25.9 & 25.1 & 24.3 \\
\hline
\end{tabular}

$12-18^{\circ} \mathrm{C}$ - Ligeir. Frio $\quad 18-26^{\circ} \mathrm{C}$ - Confortável $\square \quad 26-31^{\circ} \mathrm{C}$ - Ligeir.

quente

$31-41{ }^{\circ} \mathrm{C}$ - Quente

$>41^{\circ} \mathrm{C}$ - Muito

quente

b) Escala de sensação térmica proposta por Monteiro e Alucci (2007) para Cidade de São Paulo

Figura 04 - Mapeamento da média mensal da sensação térmica utilizando o Índice de Temperatura Fisiológica Equivalente (PET) 
Rev. Elet. em Gestão, Educação e Tecnologia Ambiental (e-ISSN: 2236-1170)

As Tabelas 2 e 3 indicaram que as maiores frequências relativas anuais estão situadas entre a faixa de "ligeiramente quente" a "quente" com $85 \%$ e $58 \%$, respectivamente, o que permite inferir que o clima da região é caracterizado por elevada sensação térmica durante todas as estações do ano. Sob o aspecto da frequência relativa mensal, notou-se que as maiores frequências relativas, para a escala de Matzarakis e Mayer, estavam inseridas dentro da faixa de "ligeiramente quente" (Tabela 2). Dentro desta faixa, com exceção do mês de setembro, caracterizado por elevadas frequências de sensação variando de "muito quente" a "extremamente quente", foi possível verificar elevação da frequência relativa de outubro a março (estação de primavera e verão) e declínio de abril a agosto (outono e inverno). Comportamento semelhante foi observado na escala proposta por Monteiro e Alucci para a sensação "quente", com exceção do mês de março, no qual houve declínio da frequência relativa. Observa-se na escala proposta por Monteiro e Alucci, que houve predomínio das frequências relativas mensais dentro da faixa de conforto térmico (Tabela 3), diferentemente do que aconteceu na escala proposta por Matzarakis e Mayer (Tabela 2).

Tabela 02 - Frequência relativa mensal da sensação térmica avaliada pelo índice PET para a região segundo a escala proposta por Matzarakis e Mayer (1996)

\begin{tabular}{c|ccccccc}
\hline Intervalo & $<13{ }^{\circ} \mathrm{C}$ & $13-18{ }^{\circ} \mathrm{C}$ & $18-23{ }^{\circ} \mathrm{C}$ & $23-29{ }^{\circ} \mathrm{C}$ & $29-35{ }^{\circ} \mathrm{C}$ & $35-41{ }^{\circ} \mathrm{C}$ & $>41{ }^{\circ} \mathrm{C}$ \\
\hline Set & $0 \%$ & $0 \%$ & $0 \%$ & $33 \%$ & $33 \%$ & $13 \%$ & $21 \%$ \\
Out & $0 \%$ & $0 \%$ & $0 \%$ & $50 \%$ & $21 \%$ & $29 \%$ & $0 \%$ \\
Nov & $0 \%$ & $0 \%$ & $0 \%$ & $54 \%$ & $25 \%$ & $21 \%$ & $0 \%$ \\
Dez & $0 \%$ & $0 \%$ & $0 \%$ & $54 \%$ & $17 \%$ & $25 \%$ & $4 \%$ \\
Jan & $0 \%$ & $0 \%$ & $0 \%$ & $54 \%$ & $25 \%$ & $21 \%$ & $0 \%$ \\
Fev & $0 \%$ & $0 \%$ & $0 \%$ & $58 \%$ & $25 \%$ & $17 \%$ & $0 \%$ \\
Mar & $0 \%$ & $0 \%$ & $0 \%$ & $63 \%$ & $17 \%$ & $21 \%$ & $0 \%$ \\
Abr & $0 \%$ & $0 \%$ & $0 \%$ & $54 \%$ & $17 \%$ & $29 \%$ & $0 \%$ \\
Mai & $0 \%$ & $0 \%$ & $42 \%$ & $25 \%$ & $13 \%$ & $21 \%$ & $0 \%$ \\
Jun & $0 \%$ & $8 \%$ & $38 \%$ & $21 \%$ & $13 \%$ & $21 \%$ & $0 \%$ \\
Jul & $0 \%$ & $0 \%$ & $42 \%$ & $25 \%$ & $13 \%$ & $21 \%$ & $0 \%$ \\
Ago & $0 \%$ & $0 \%$ & $29 \%$ & $29 \%$ & $13 \%$ & $29 \%$ & $0 \%$ \\
\hline Ano & $0 \%$ & $1 \%$ & $13 \%$ & $43 \%$ & $19 \%$ & $22 \%$ & $2 \%$ \\
\hline
\end{tabular}

Com relações as médias mensais de PET (Figura 5), ao se analisar os intervalos propostos por Matzarakis e Mayer, os meses de fevereiro, março e de maio a agosto classificaram-se com sensação térmica no intervalo de "ligeiramente quente". Os meses de setembro a janeiro e de abril se inseriram no intervalo de "quente". Comparados estes resultados com a escala proposta para cidade de São Paulo, notou-se alteração de comportamento quanto à sensação térmica observada para a região. Somente os meses de setembro e dezembro ficaram inseridos no intervalo de "quente", enquanto as demais médias ficaram inseridas na escala de "ligeiramente quente". Isso ratifica a afirmação feita anteriormente de que habitantes de clima tropical estão mais adaptados ao calor que os de clima temperado. Como se pode observar, em nenhum mês do ano a média mensal de PET ficou inserida dentro da faixa de conforto térmico, provavelmente porque os limites para região de clima tropical continental sejam diferentes tanto dos definidos por Matzarakis e Mayer quanto Monteiro e Alucci. Assim, como o clima tropical sofre variações ao longo do território brasileiro, os resultados sugerem a necessidade de calibração das escalas do PET para as diferentes localidades. 
Rev. Elet. em Gestão, Educação e Tecnologia Ambiental (e-ISSN: 2236-1170)

Tabela 03 - Frequência relativa mensal da sensação térmica avaliada pelo índice PET para a região segundo a escala proposta por Monteiro e Alucci (2007)

\begin{tabular}{c|cccccc}
\hline Intervalo & $<13{ }^{\circ} \mathrm{C}$ & $13-18{ }^{\circ} \mathrm{C}$ & $18-26{ }^{\circ} \mathrm{C}$ & $26-31{ }^{\circ} \mathrm{C}$ & $31-41{ }^{\circ} \mathrm{C}$ & $>41{ }^{\circ} \mathrm{C}$ \\
\hline Set & $0 \%$ & $0 \%$ & $13 \%$ & $33 \%$ & $33 \%$ & $21 \%$ \\
Out & $0 \%$ & $0 \%$ & $33 \%$ & $25 \%$ & $42 \%$ & $0 \%$ \\
Nov & $0 \%$ & $0 \%$ & $38 \%$ & $25 \%$ & $38 \%$ & $0 \%$ \\
Dez & $0 \%$ & $0 \%$ & $17 \%$ & $42 \%$ & $38 \%$ & $4 \%$ \\
Jan & $0 \%$ & $0 \%$ & $29 \%$ & $33 \%$ & $38 \%$ & $0 \%$ \\
Fev & $0 \%$ & $0 \%$ & $46 \%$ & $21 \%$ & $33 \%$ & $0 \%$ \\
Mar & $0 \%$ & $0 \%$ & $54 \%$ & $17 \%$ & $29 \%$ & $0 \%$ \\
Abr & $0 \%$ & $0 \%$ & $38 \%$ & $25 \%$ & $38 \%$ & $0 \%$ \\
Mai & $0 \%$ & $0 \%$ & $54 \%$ & $17 \%$ & $29 \%$ & $0 \%$ \\
Jun & $0 \%$ & $8 \%$ & $46 \%$ & $13 \%$ & $33 \%$ & $0 \%$ \\
Jul & $0 \%$ & $0 \%$ & $54 \%$ & $17 \%$ & $29 \%$ & $0 \%$ \\
Ago & $0 \%$ & $0 \%$ & $50 \%$ & $17 \%$ & $33 \%$ & $0 \%$ \\
\hline Ano & $0 \%$ & $1 \%$ & $39 \%$ & $24 \%$ & $34 \%$ & $2 \%$ \\
\hline
\end{tabular}

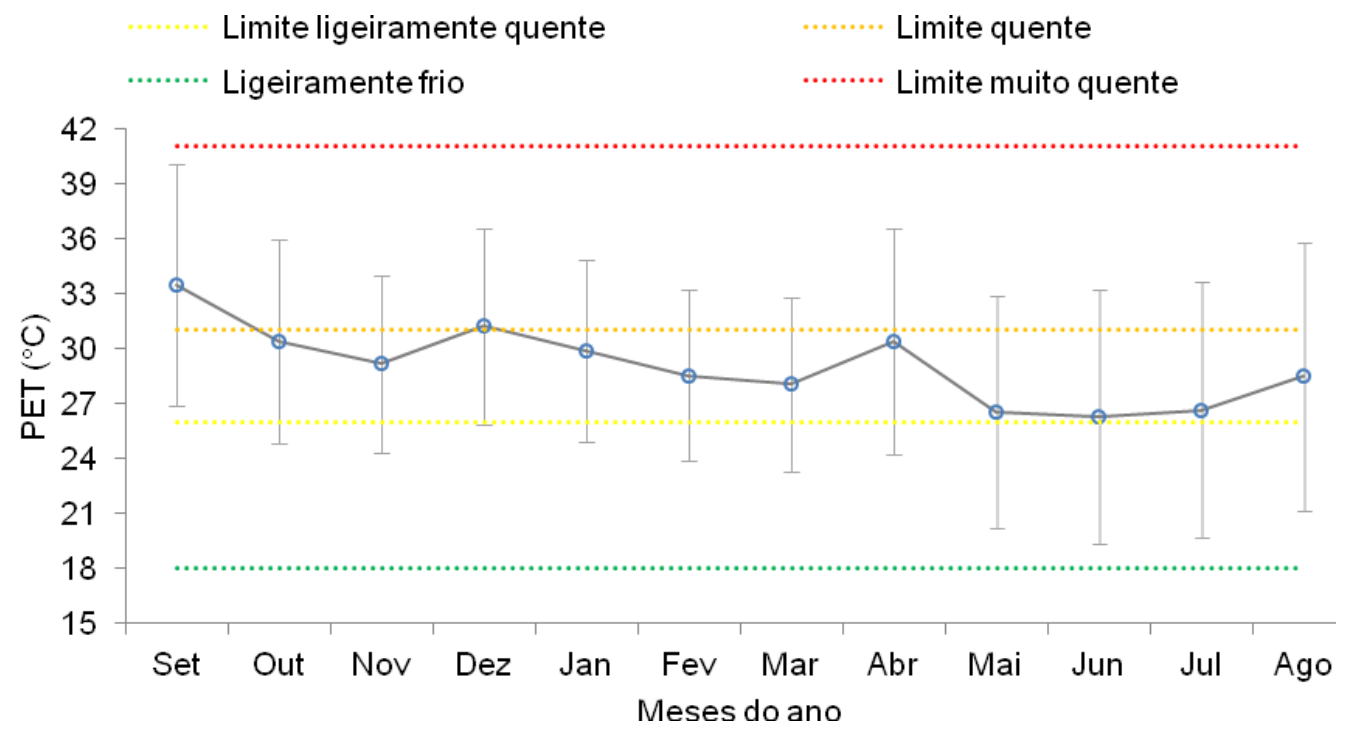

Figura 05 - Média mensal da sensação térmica para o índice PET. Linhas delimitativas para a escala de PET proposta por Monteiro e Alucci

\section{CONSIDERAÇÕES FINAIS}

Esta pesquisa teve por objetivo avaliar a sensação térmica em espaços urbanos a céu aberto, a partir do índice preditivo Temperatura Fisiologica Equivalente (PET), com vistas a verificar sua aplicabilidade em região de clima tropical.

Os resultados indicaram que a sensação térmica de conforto, definida a partir da calibração proposta para países europeus, raramente foi alcançada durante o ano pesquisado. Exceção acontece nos meses mais frios do ano (maio, junho e julho), apenas durante o periodo 
Rev. Elet. em Gestão, Educação e Tecnologia Ambiental (e-ISSN: 2236-1170)

noturno. Quando se utiliza a escala definida para a cidade de São Paulo, com clima tropical, notase que em todos os meses do ano a faixa de conforto térmico foi alcançada, também durante o período noturno.

Durante o periodo diurno, o conforto térmico a céu aberto não foi alcançado em nenhum mês do ano, Nesse periodo, ambas as escalas indicaram sensação térmica de calor, com variação na sensação de calor para mais ou para menos. Setembro se caracterizou como mês de maior frequência relativa de horas com desconforto térmico, com sensação variando de "ligeiramente quente" a "extremamente quente" na escala proposta por Matzarakis e Mayer, e "confortável" a "muito quente" na proposta por Monteiro e Alucci. O mês de junho apresentou maior número de horas de conforto térmico, com sensação variando de "ligeramente frio" a "muito quente" na escala proposta por Matzarakis e Mayer, e "ligeirmante frio" a "quente" na escala proposta por Monteiro e Alucci.

O comportamento de sensação térmica sempre a menor na escala proposta por Monteiro e Alucci indica que os habitantes de locais de clima tropical estão mais adaptados ao calor que os de clima temperado. As médias mensais de PET ratificam esse comportamento e sugerem que os limites de conforto térmico para regiões de clima tropical continental sejam diferentes dos definidos por Monteiro e Alucci, havendo desta forma, a necessidade de calibração do Índice da Temperatura Fisiológica Equivalente (PET).

Os resultados confirmam a hipótese de que a região onde a pesquisa foi desenvolvida impõe condições bioclimáticas desfavoráveis sob condições a céu aberto, indicando a necessidade do uso de estratégias bioclimaticas que ajudem a aprimorar ou reduzir os efeitos ocasionados pelo clima local. Nesse sentido, o sombreamento, artificial ou arbóreo, pode ajudar a melhorar a sensação térmica. A morfologia urbana é outro aspecto que deve ser avaliado na cidade, visto que ela pode favorecer a circulação de ar e reduzir a energia armazenada dentro do dossel urbano, minimizando a intensidade de ilha de calor e melhorando as condições termo-higrométrica das cidades. Aponta-se, como estratégia local, a necessidade de uma política de manutenção e ampliação da arborização no meio urbano, com vistas à promoção de melhorias do conforto térmico para os pedestres.

\section{AGRADECIMENTOS}

Agradecemos à Fundação de Amparo à Pesquisa de Mato Grosso (FAPEMAT) pelo suporte financeiro à esta pesquisa.

\section{REFERÊNCIAS}

ABREU, L. V.; LABAKI, L. C. Conforto térmico propiciado por algumas espécies arbóreas: avaliação do raio de influência através de diferentes índices de conforto. Ambiente Construído, Porto Alegre, v. 10, n. 4, p. 103-117, 2010.

AYOADE, J. O. Introdução a climatologia para os trópicos. Rio de Janeiro: Bertrand Brasil, 2001.

CALlejAS, I. J. A., DURANTE, L. C, NOGUEIRA, M. C. J. A., NOGUEIRA, J. S, CAMPOS, A. C. S., 2011. Estudo do sombreamento arbóreo, atenuação da radiação solar e microclima dos pátios escolares: elementos para se pensar a sustentabilidade urbana. In: IV Encontro Latino-Americano de Construções Sustentáveis. Vitória. Anais... Vitória, v.1, p.1-10, 2011. 
CALLEJAS, I. J. A. Avaliação temporal do balanço de energia em ambientes urbanos na cidade de Cuiabá-MT. Cuiabá, 2012. 265f. Tese (Doutorado), Programa de Pós-graduação em Física Ambiental, Universidade Federal de Mato Grosso, Cuiabá, 2012.

CAMPELO JUNIOR, J. H.; PRIANTE FILHO, N.; CASEIRO, F. T. Caracterização macroclimática de Cuiabá. In: III Encontro Nacional de Estudos sobre o Meio Ambiente, Londrina. Anais... Londrina, 1991.

DUARTE, D. H. S. Padrões de Ocupação do Solo e Microclimas Urbanos Na Região de Tropical Continental. 2000. 278f. Tese (Doutorado em Arquitetura) - Universidade de São Paulo, São Paulo.

FANGER, P. O. Thermal Comfort, McGraw Hill, New York, 1972.

FAUSTINI, F. B.; FONTES, M. S. G. C. Conforto térmico em espaços públicos de passagem: estudos no calçadão da Batista de Carvalho em Bauru-SP, Brasil. In: PLURIS 2010 - 4. Congresso Lusobrasileiro para o Planejamento Urbano, Regional, Integrado, Sustentável, Faro, Portugal. Anais...Faro: Pluris, v.1, 2010.

FIALA, D.; HAVENITH, G.; BRÖDE, P.; KAMPMANN, B.; JENDRITZKY, G. UTCI-Fiala multi-node model of human temperature regulation and thermal comfort. Int J Biometeorol, special issue, 2011.

GAGGE, A. P.; FOBELETS, A. P.; BERGLUND, L. G. A. Standard predictive index of human response to the thermal environment. ASHRAE Transactions, 92, p.709-31, 1986.

HIRASHIMA, S. Q. S.; ASSIS, E. S.; FERREIRA, D. G. Calibração do Índice de Conforto Térmico Temperatura Equivalente Fisiológica (PET) para Espaços Abertos do Município de Belo Horizonte MG. In: XI Encontro Nacional de Conforto no Ambiente Construído e VII Encontro Latino Americano de Conforto no Ambiente Construído, 2011, Armação de Búzios, RJ. Anais...Armação de Búzios: ENTAC, 2011.

HÖPPE, P. The physiological equivalent temperature - a universal índex for the biometeorological assessment of the thermal environment, Int J Biometeorol, 43, 71-75, 1999.

IBGE. Instituto Brasileiro de Geografia e Estatística. Disponível: http://www.ibge.gov.br. [Acessado 10 Abril 2011].

IPDU. Instituto de Pesquisas e Desenvolvimento Urbano. Perfil Socioeconômico de Cuiabá. Cuiabá: Central de Texto, 2009.

ISO 7726. International Stardard Organization. Ergonomics of the thermal environments: Instruments and methods for measuring physical quantities. 1998. 
LABAKI, L. C.; FONTES, M. S. G. C.; BARTHOLOMEI, C. L. B.; DACANAL, C. Conforto térmico em espaços públicos de passagem: estudos em ruas de pedestres no estado de São Paulo. Ambiente Construído, Porto Alegre, v. 12, n. 1, p.167-183, 2012.

LIN, T. P.; MATZARAKIS, A.; HWANG, R. L.; YING-CHE HUANG, Y. C. Effect of pavements albedo on long-term outdoor thermal comfort, Building and Environment, v.45, p.213-221, 2010.

MAITTELLI, G. T. Uma Abordagem Tridimensional de Clima Urbano em Área Tropical Continental. O Exemplo de Cuiabá - MT. São Paulo, 1994. Tese de Doutorado (Faculdade de Filosofia e Ciências Humanas), Universidade de São Paulo.

MATZARAKIS, A; MAYER, H. Another kind of environmental stress: thermal stress. WHO News. N.18, p.7-10, 1996.

MATZARAKIS, A.; MAYER, H.; IZIOMON, M. G. Applications of a universal thermal index: physiological equivalent temperature. Int J Biometeorol, 43, p.76-84. 1999.

MATZARAKIS, A., RUTZ, F., MAYER, H., Aplicativo computacional Ray Man 1.2. Disponível: www.mif.unifreiburg.de/rayman/2000. [Acesso 10 Abril 2011].

MONTEIRO, L. M; ALUCCI, M. P. Calibration of outdoor thermal comfort models. In: INTERNATIONAL CONFERENCE ON PASSIVE AND LOW ENERGY ARCHITECTURE, 23, 2006. Proceedings...Genève: Université de Genève, p.515-522, 2006.

MONTEIRO, L. M.; ALUCCI, M. P. Conforto térmico em espaços abertos com diferentes abrangências microclimáticas: parte 2: proposição de calibração de modelos preditivos. In: ENCONTRO NACIONAL, 9., ENCONTRO LATINO AMERICANO DE CONFORTO NO AMBIENTE CONSTRUÍDO, 5., 2007, Ouro Preto. Anais... Porto Alegre: ANTAC, p.1231-1240, 2007.

NIKOLOPOULOU M.; BAKER, N.; STEEMERS, K. Thermal comfort in outdoor urban spaces: understanding the human parameter. Solar Energy, v.70, n. 3, p.227-235, 2001.

SANT'ANNA NETO, J. L. Mudanças Climáticas Globais: Implicações no Desenvolvimento Econômico e na Dinâmica Natural. Revista Pantaneira, v. 2, n. 2, p.66-78, 2000.

SOUZA, C. F., TINÔCO, I. F. F., BAÊTA, F. C., FERREIRA, W. P. M., SILVA, R. S. Avaliação de materiais alternativos para confecção do termômetro de globo. Ciênc. Agrotec., Lavras, n.1, p.157-164, 2002. 
Rev. Elet. em Gestão, Educação e Tecnologia Ambiental (e-ISSN: 2236-1170)

Identificação dos Autores:

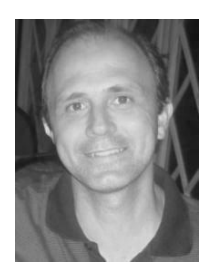

Ivan Julio Apolonio Callejas

Graduação em Engenharia Civil pela Universidade Federal de Mato Grosso/ UFMT;

Professor Efetivo do Departamento de Arquitetura e Urbanismo/ UFMT;

Doutor pelo Programa de Pós Graduação em Física Ambiental/ PPGFA/ UFMT, Linha de Pesquisa: Análise Microclimática em Sistemas Urbanos, E-mail: ivancallejas@ig.com.br

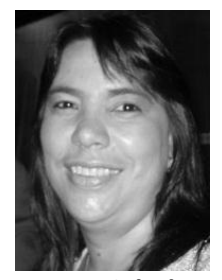

Marta Cristina de Jesus Albuquerque Nogueira

Graduação em Engenharia Civil pela Universidade Federal de Mato Grosso/ UFMT;

Professor Efetiva do Departamento de Arquitetura e Urbanismo/ UFMT;

Professora do Programa de Pós Graduação em Física Ambiental/ PPGFA/ UFMT, Linha de Pesquisa: Análise

Microclimática em Sistemas Urbanos, E-mail: mcjanp@gmail.com 